\title{
TRANSFORMATIONAL FACTORS OF THE DEVELOPMENT AND IMPLEMENTATION OF THE INNOVATION CAPACITY OF REGIONAL ECONOMY
}

\author{
Igor V. Antonenko \\ Volgograd State University, Volgograd, Russian Federation \\ Tatiana S. Sidorovich \\ Volgograd State University, Volgograd, Russian Federation
}

\begin{abstract}
The author focuses on the analysis of the conditions necessary for the development of innovation capacity of economy and distinguishes two groups of factors - transformational factors (presented by the human factor $-A$, technological factor $-T$, natural factor $-R n$ ) and transactional factors (presented by the institutional factor - Ins, organizational factor $-O$, informational factor - Inf) - contributing to the development of innovation capacity. Human capital is the historical form of the human factor with intellectual capital as its integral component in the form of resources of intellectual activity which enhances the intellectual capacity and innovation capacity of the region. The technical factor which contributes to the development of the innovation capacity of economy implements the resource element of innovation capacity and results in knowledge-intensive industries where technological changes are defined by the sectoral and technological specialization and differ by their degree of knowledge intensity. The nature factor plays an important role in the development of the innovation capacity of economy, defines its technological base and has an impact on the scale of innovation activity. Natural recourses influence innovation capacity by means of the components of natural environment which are used as means of production or commodities. The role of the nature-resource factor in the structure of innovation capacity and innovation system increases with the abundance of extractive industries and decreases with the processing of raw materials. The human factor is considered to be the major one for the development of innovation capacity, it integrates the functions of technological, organizational and nature factors and contributes to the implementation of the innovation capacity of economy.

Key words: transformational factors, transactional factors, innovation capacity, regional innovation system, regional economy, knowledge generation, innovation infrastructure.
\end{abstract}

Citation. Antonenko I.V., Sidorovich T.S. Transformational Factors of the Development and Implementation of the Innovation Capacity of Regional Economy. Journal of Volgograd State University. Economics, 2020, vol. 22, no. 2, pp. 86-95. (in Russian). DOI: https://doi.org/10.15688/ek.jvolsu.2020.2.8

УДК 332.1

Дата поступления статьи: 10.03.2020

ББК 65.04

Дата принятия статьи: 13.04.2020

\section{ТРАНСФОРМАЦИОННЫЕ ФАКТОРЫ ФОРМИРОВАНИЯ И РЕАЛИЗАЦИИ ИННОВАЦИОННОГО ПОТЕНЦИАЛА РЕГИОНАЛЬНОЙ ЭКОНОМИКИ}

\author{
Игорь Владимирович Антоненко \\ Волгоградский государственный университет, г. Волгоград, Российская Федерация \\ Татьяна Станиславовна Сидорович \\ Волгоградский государственный университет, г. Волгоград, Российская Федерация
}

Аннотация. Использование факторного похода к анализу предпосылок формирования инновационного потенциала хозяйственной системы позволило выделить группу трансформационных (представлены: че- 
ловеческий - $A$, технико-технологический - $T$, природный $-R n$ ) и трансакционных (представлены: институциональный - Ins, организационный - $O$, информационный - Inf) факторов, способствующих развитию указанного потенциала. Исторической формой человеческого фактора является человеческий капитал, где составной его частью становится интеллектуальный капитал в виде ресурсов интеллектуальной деятельности, который способствует формированию интеллектуального потенциала, характеризующего внутренние возможности развития инновационного потенциала региона. Технико-технологический фактор, способствующий формированию инновационного потенциала хозяйственной системы, реализует ресурсный элемент инновационного потенциала, что определяет результат его реализации в виде наукоемких производств, где направления технологических изменений зависят от отраслевой и технологической специализации и различаются в зависимости от степени их наукоемкости. Природный фактор играет важную роль в процессе формирования инновационного потенциала хозяйственной системы, определяет его технико-технологическую базу и влияет на масштабы инновационной деятельности. Природные ресурсы воздействуют на инновационный потенциал теми компонентами природной среды, которые используются в качестве средств производства или предметов потребления. Роль природно-ресурсного фактора в структуре инновационного потенциала и инновационной системы возрастает при преобладании добывающих отраслей и снижается по мере повышения степени обработки сырья. Человеческий фактор объединяет и интегрирует функции технико-технологического, организационного и природного факторов, что во многом способствует реализации инновационного потенциала хозяйственной системы.

Ключевые слова: трансформационные факторы, трансакционные факторы, инновационный потенциал, региональная инновационная система, региональная экономика, генерация знаний, инновационная инфраструктура.

Цитирование. Антоненко И. В., Сидорович Т. С. Трансформационные факторы формирования и реализации инновационного потенциала региональной экономики // Вестник Волгоградского государственного университета. Экономика. - 2020. - Т. 22, № 2. - С. 86-95. - DOI: https://doi.org/10.15688/ek.jvolsu.2020.2.8

\section{Введение}

Понятием «фактор» оперируют многие общественные и естественные науки, что позволяет определить причину, характер или отдельные черты какого-либо явления, а также движущие силы какого-либо процесса [Большая Советская ..., 2008]. В данном случае необходимо выявить факторы, влияющие на формирование инновационного потенциала национальной инновационной системы на основе анализа его структуры и определяющих элементов.

В ряде работ факторы, определяющие инновационный потенциал хозяйственной системы, трактуются по-разному.

Так, Д.И. Кокурин, В.М. Шепелев составной частью инновационного потенциала считают ресурсный потенциал, который создает возможности развития первого, в результате чего ресурс инновационной деятельности становится фактором [Кокурин и др., 2002, с. 79-80]. При этом авторы выделяют объективные и субъективные, внутренние и внешние факторы инновационного потенциала.

Количественные параметры инновационного потенциала определяются объективными факторами его внутренней среды, способ- ствующими созданию и распространению новшеств, а субъективные факторы проявляются в процессе принятия решений по нововведениям, субъектами инновационного процесса. Ко внутренним относятся факторы, определяющие состояние институциональных связей (форма собственности субъектов инновационной деятельности, их организационно-правовая структура, отраслевая принадлежность субъекта и др.), а внешние факторы предопределяют состояние ресурсного потенциала инновационной деятельности [Кокурин и др., 2002 , с. $80-87]$.

Отметим, что безусловным достоинством указанной концепции является исследование субъектно-объектной структуры инновационного потенциала, включающей способности субъекта к использованию имеющихся ресурсов и определяемой институциональными связями экономической системы. Недостатком указанной концепции является фрагментарный анализ состояния факторов внешней среды, определяемый составом ресурсов и отсутствием внимания к институциональной составляющей инновационной деятельности. Также не представлены факторы, формирующие результативный блок иннова- 
ционного потенциала, характеризующий уровень развития предпринимательской среды на макро-, мезо- и микроуровнях.

А.Г. Большов в структуре инновационного потенциала национальной экономики выделяет факторы развития, накопления и активизации этого потенциала [Большов, 2007, c. $30-31]$.

Недостатком данной классификации является нечеткая структурированность факторов, что не позволяет выявить взаимосвязи, формирующие инновационный потенциал национальной экономики. Также отметим, что согласно фактору 1 (расширенное воспроизводство инновационного потенциала за счет внутренних источников) указанной классификации развитие инновационного потенциала происходит не только за счет внутренних источников, но и посредством институциональных взаимосвязей, организационной структуры, инновационной инфраструктуры и др. Кроме того, фактор 2 (использование части природной ренты на накопление и развитие инновационного потенциала) рассматривается автором как источник финансирования инновационного потенциала, а не как фактор, направленный на формирование, развитие и реализацию инновационного потенциала экономической системы. Согласно фактору 3 (формирование социально-психологических и социально-экономических механизмов, вовлекающих талантливую молодежь в сферы науки, образования, техники) необходимо создавать не только механизмы, вовлекающие молодежь в сферы науки и техники, но и мотивационные стимулы, позволяющие реализовать их способности, что создаст предпосылки реализации инновационного потенциала экономической системы. Согласно фактоpy 4 (формирование в науке, образовании, технике механизмов расстановки кадров в соответствии с их способностями) необходимо формировать механизмы не расстановки кадров, а передачи знаний, характеризующиеся эффективной деятельностью организаций инновационной инфраструктуры, что создаст предпосылки реализации ресурсного элемента инновационного потенциала.

А.Н. Фоломьев выделяет первичные факторы-ресурсы и вторичные факторы-процессы. Вторичные факторы обусловливают использование первичных [Фоломьев, 2004, c. 79-80].

На наш взгляд, неправомерно отождествлять ресурсную и факторную составляющие инновационного потенциала, так как ресурс не всегда может быть задействован и тем самым не сможет повлиять на результат реализации инновационного потенциала экономической системы. Кроме того, автором акцент делается именно на ресурсной составляющей инновационного потенциала, что не позволяет выявить мотивационные, внешние и внутренние возможности формирования инновационного потенциала.

Также в качестве недостатка в указанной концепции отметим отсутствие базовых факторов развития инновационной системы, а именно управляющей, производственной и передающих знания подсистем, что не отражает уровни формирования и развития инновационного потенциала в структуре инновационной системы.

В.Л. Шмелев выделяет внутренние и внешние факторы инновационного потенциала [Шмелев, 2006, с. 33-34]. К факторам внешней среды можно отнести политические и макроэкономические факторы, влияющие на развитие инновационной деятельности в стране. На наш взгляд, автором не учитываются в составе внешней среды формирование мотивационной составляющей инновационного потенциала, что является важной функцией органов государственного управления.

Однако наиболее важным для осуществления инновационной деятельности, по мнению В.Л. Шмелева, является наличие внутренних факторов инновационного потенциала предприятия, который характеризуется как совокупность различных ресурсов, включая: интеллектуальные; материальные; финансовые; кадровые; инфраструктурные ресурсы [Шмелев, 2006, c. 33].

В данном случае автором неправомерно отождествляется понятие ресурсов и факторов, а инновационный потенциал характеризуется посредством ресурсной составляющей, что не в полной мере определяет его сущностные характеристики. На наш взгляд, указанные факторы слабо структурированы, не прослеживается связь между структурой инновационного потенциала и структурой нацио- 
нальной и региональной инновационными системами, где на уровне «управление - регулирование» формируются внешние и мотивационные возможности развития инновационного потенциала, элементом «Генерация знаний»внутренние возможности развития инновационного потенциала, элементом «Инновационная инфраструктура» - реализация ресурсного элемента инновационного потенциала, а элементом «Предпринимательский сектор» - результат реализации инновационного потенциала.

\section{Результаты и обсуждение}

Для объяснения противоречивых отношений в формировании инновационного потенциала региональной инновационной системы целесообразно применить теорию эндогенных факторов производства О.В. Иншакова, которая позволит, во-первых, исследовать формирование и развитие Региональной инновационной системы и ее потенциала в условиях индустриализации и постиндустриализации.

Воспользуемся факторным подходом, предложенным О.В. Иншаковым, который выделяет две группы факторов производства [Иншаков, 2002, с. 59-61] - трансформационные (представлены $A$ - человеческим, $T$ техническим, $R n$ - природным факторами) и трансакционные (эта группа представлена Ins - институциональным, $O$ - организационным, Inf - информационным факторами).

Трансформационные факторы преобразуют природное вещество в нужные людям формы, а трансакционные - определяют систему взаимодействия между различными хозяйствующими субъектами, где все и каждый из выделенных основных факторов приобретают особую всеобщую форму капитала [Иншаков, 2002, с. 62].

Исследуем инновационные составляющие человеческого фактора, формирующие внутренние возможности реализации инновационного потенциала экономической системы.

Актуальной исторической формой человеческого фактора стал человеческий капитал индивида, являясь результатом определенного объема инвестиций в человека.

Функцией человеческого капитала является создание и распространение инноваций, а также условий, позволяющих эффективно формировать и реализовывать существующий инновационный потенциал. Следовательно, составной частью человеческого капитала является интеллектуальный капитал в виде ресурсов интеллектуальной деятельности, который определяет особенности развития национальных технологических способностей по обеспечению процесса внедрения новых технологий в производство [Бойко, 2005, с. 154] и способствует формированию интеллектуального потенциала человеческой деятельности.

В свою очередь, основой интеллектуального потенциала страны или региона является развитие науки, уровень и качество образования специалистов, а развитие наукоемких отраслей во многом зависит от использования человеческого интеллекта, генерирующих инновационный потенциал территорий [Келле, 2003, с. 37].

Следовательно, исследование динамики и перспектив развития интеллектуального потенциала регионов ЮФО позволит выявить тенденцию к становлению региональной экономики, основанной на знаниях, посредством определения степени ее влияния на валовой региональный продукт. В свою очередь это позволит исследовать элемент «Генерация знаний» в структуре инновационной системы и выявить внутренние возможности формирования инновационного потенциала территории.

Проведенные расчеты индекса развития интеллектуального потенциала (ИРИП) для регионов ЮФО (см. таблицу) показали, что лидирующие позиции в 2019 г. по данному индексу принадлежат регионам, обладающим большим количеством высших учебных заведений и научно-исследовательских институтов (Ростовская, Астраханская, Волгоградская область), а значительная часть регионов ЮФО обладает сравнительно небольшим уровнем интеллектуального потенциала.

Далее выявим составляющие инновационного потенциала технического фактора, использующие ресурсный элемент инновационного потенциала и способствующие формированию результата его реализации.

Техника как фактор производства «...включает и технологию как внутренний закон, определяющий структурные и функциональные формы ее существования... Актуальной исторической формой этого фактора 


\section{Индекс развития интеллектуального потенциала, регионы ЮФО}

\begin{tabular}{|l|c|c|c|}
\hline \multicolumn{1}{|c|}{ Южный федеральный } & $\begin{array}{c}\text { Индекс развит. } \\
\text { интел. потенц. } \\
2017 \text { г. }\end{array}$ & $\begin{array}{c}\text { Индекс развит. } \\
\text { интел. потенц. } \\
2018 \text { г. }\end{array}$ & $\begin{array}{c}\text { Индекс развит. } \\
\text { интел. потенц. } \\
2019 \text { г. }\end{array}$ \\
\hline Ростовская область & 0,826 & 0,764 & 0,687 \\
\hline Астраханская область & 0,294 & 0,389 & 0,420 \\
\hline Волгоградская область & 0,472 & 0,498 & 0,503 \\
\hline Республика Адыгея & 0,381 & 0,411 & 0,452 \\
\hline Краснодарский край & 0,513 & 0,499 & 0,414 \\
\hline Республика Калмыкия & 0,271 & 0,376 & 0,365 \\
\hline Республика Крым & 0,291 & 0,352 & 0,372 \\
\hline г. Севастополь & 0,314 & 0,402 & 0,489 \\
\hline
\end{tabular}

Примечание. Составлено авторами по: [Наука и инновации ...].

стал технический (но не «физический») капитал, определяющий глобальное лидерство развитых стран..» [Иншаков, 2002, с. 64-65].

Экономическую сущность технического фактора, характеризует степень технического и технологического развития производства, что служит предпосылкой появления наукоемких производств и приводит к повышению отдачи капитала и трудового фактора [Евченко и др., 2000, с. 149].

В структуре национальной экономики источники и направления технологических изменений среди отраслей различной степени наукоемкости существенно разнятся, что влияет на варианты инновационного поведения экономических субъектов, зависящие от отраслевой и технологической специализации, размера инновационной фирмы, типа товара, инновационных целей, источников инноваций, наличия инновационной инфраструктуры и институтов развития.

Таким образом, технический фактор, способствующий формированию инновационного потенциала региональной экономики, реализует ресурсный элемент инновационного потенциала, что определяет результат его реализации в виде наукоемких производств, а направления технологических изменений зависят от отраслевой и технологической специализации и различаются в зависимости от степени их наукоемкости [Белова, 2019].

Отраслевая специфика в отношении источников инноваций и технологий характеризуется технологическими траекториями инновационного развития регионов ЮФО, которые имеют тенденцию к сближению, вследствие чего целесообразно поддерживать высокий уровень технологизации экономики регионов ЮФО посредством заимствования технологий, а также перейти от системы закрытых инноваций к открытым.

В рамках отраслевой траектории производства наукоемких продуктов выделены отрасли специализации с высоким технологическим уровнем развития, такие как производство электронного и оптического оборудования, химическое производство, что предполагает поиск новых, технологически связанных между собой рынков.

В рамках отраслевой траектории специализированных поставок, лидирующее положение по уровню инновационности занимает производство машин и оборудования, что предполагает развитие технологий, являющихся основой для модификации продукта.

В рамках отраслевой траектории со значимым эффектом масштаба, лидирующее положение занимает обрабатывающее производство, что предполагает развитие внутренних подразделений НИОКР на предприятиях и формирование собственной стратегии научных исследований.

Далее исследуем составляющие инновационного потенциала природного фактора, формирующего ресурсный элемент инновационного потенциала хозяйственной системы.

Актуальной исторической формой этого фактора стал природный капитал, когда «природные ресурсы могут быть использованы в настоящем за счет инноваций, черпаемых из будущего» [Бабурин, 2002, с. 17].

Наличие природных ресурсов является одним из основных условий, определяющих характер развития хозяйственной системы и 
возможности реализации ее инновационного потенциала. Количество и качество, а также сочетание ресурсов определяют природноресурсный потенциал хозяйственной системы, что позволяет развивать инновационный потенциал региональной экономики при наличии высокотехнологичного производства на данной территории. Современные технологии привели к почти полному задействованию природной среды в экономической деятельности общества, обеспечивая воздействие человека на региональные инновационные системы посредством распространения и применения новых ресурсосберегающих технологий [Сигов, 2007, с. 62].

Отметим, что «формирование инновационного потенциала затруднено ограниченными возможностями получения материальных ресурсов» [Кокурин и др., 2002, с. 78-79]. Следовательно, материально-технические и природные ресурсы занимают важное место в процессе формирования инновационного потенциала хозяйственной системы, формируя его вещественную основу, определяя технико-технологическую базу, наращивая темпы инновационной деятельности [Суглобов и др., 2019].

Используя методологию системного анализа, представим трансакционные и трансформационные факторы формирования инновационного потенциала РИС в виде модели «черного ящика» с входом-выходом, прямыми и обратными связями.

Теория систем рассматривает два вида связей - прямые (обеспечивают передачу воздействия с выхода одного элемента на вход другого, следовательно при увеличении факторного признака будет расти и результативный, и наоборот), обратные связи (обеспечивают передачу воздействия с выхода некоторого элемента на вход того же элемента, либо непосредственно, либо через другие элементы, то есть увеличение факторного признака будет уменьшать результативный).

В зависимости от характера управления выделяют отрицательные связи (обеспечивают поддержание системы в заданном состоянии) и положительные (обеспечивают перевод системы в новое состояние, которое будет зависеть от конкретной ситуации). Вследствие того, что в экономических системах практически отсутствуют цели, состоящие в поддержании некоторых параметров на заданном уровне, основной тип обратных связей в экономике положительный.

Отметим, что для развития системы необходимо, чтобы в контуре присутствовали положительные обратные связи [Могилевский, 1999, с. 234]. Посредством их осуществляется взаимовлияние всех элементов системы, а изменение состояния какого-либо элемента влияет на состояния всех других элементов и системы в целом.

Функция ограничения складывается из трех частей: ограничений входа (нехватка высококвалифицированного персонала, отсутствие источников инновационного инвестирования, неразвитая информационная база), ограничений выхода (рыночный спрос) и ограничений связей управления.

В процессе анализа, нами были выявлены следующие взаимозависимости между трансформационными и трансакционными факторами, влияющими на формирование инновационного потенциала региональной инновационной системы (см. рисунок).

Первые пары связей трансформационных и трансакционных факторов обнаружены между человеческими, техническими, организационными и природными факторами развития инновационного потенциала вследствие того, что научно-техническая и инженерно-конструкторская деятельность ученых ведет к повышению технологического уровня производства, а развитие наукоемких отраслей зависит от степени развития человеческого капитала, в то время как высокий технический уровень производства приводит к повышению отдачи производительности труда. В свою очередь технологическая и организационная структуры экономики взаимозависимы, где скорость распространения технологии зависит от способности организационной структуры меняться в зависимости от изменения внешней среды, а одной из причин структурных сдвигов выступают инновационные технологии. Технический и природный факторы взаимозависимы вследствие того, что современные технологии почти полностью задействовали природную среду в экономической деятельности общества, где природные ресурсы являются вещественной основой инновационного потенциала и определяют его технико- 


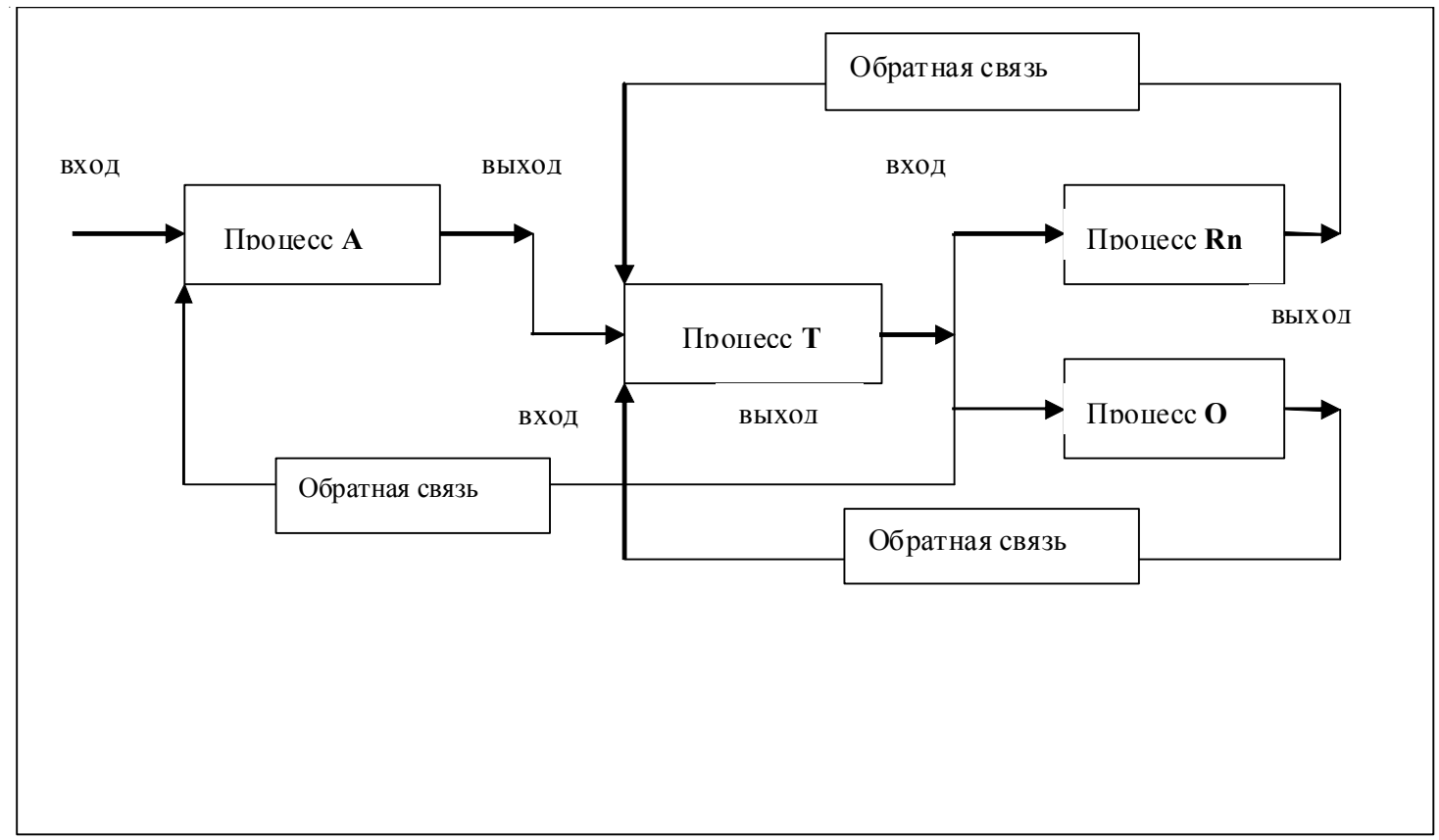

Рисунок. Схема взаимодействия трансформационных и трансакционных факторов формирования инновационного потенциала

Примечание. Составлено авторами.

технологическую базу, а также масштабы его воспроизводства. Следовательно, $A$ комплементарен $T$, в свою очередь $T$ комплементарен $O$ и $R n$, то есть $A \leftrightarrow T \leftrightarrow O \leftrightarrow R n$.

Вторая пара связей обнаружена между человеческими и организационными факторами инновационного потенциала, так как, чтобы человеческий капитал был направлен на организацию исследований и разработок, необходима соответствующая организационная структура, координирующая и управляющая деятельностью человека, включающая материально-техническую базу, инновационную инфраструктуру и т. д. Следовательно, А комплементарен $O$, то есть $A \leftrightarrow O$.

Третья пара связей обнаружена между человеческими и природными факторами инновационного потенциала вследствие того, что в процессе трансформации природных ресурсов происходит углубление разделения труда в области их переработки, следовательно $A$ комплементарен $R n$, то есть $A \leftrightarrow R n$.

Таким образом, оценить инновационный потенциал региональной инновационной системы (далее - РИС) целесообразно посредством параметров развития человеческого, технического (технологического) и природного факторов РИС.
Таким образом, выделенные нами подсистемы РИС характеризуются следующими факторными показателями развития инновационного потенциала: образовательная и научно-исследовательская подсистемы РИС характеризуется показателями развития человеческого фактора, формирующего инновационный потенциал РИС. Указанные показатели характеризуют ресурсную составляющую инновационного потенциала РИС в виде человеческого и научно-исследовательского pecypca.

Производственно-технологическая подсистема РИС характеризуется показателями развития технического фактора формирования инновационного потенциала РИС. Указанные показатели характеризуют ресурсную составляющую инновационного потенциала РИС в виде материально-технического ресурса.

Институциональная подсистема характеризуется количеством инфраструктурных элементов, наличием региональных целевых программ и концепций инновационного развития, региональных кластеров, региональных законодательных и нормативных актов в области инновационной деятельности, участием в специальных отраслевых программах инновационного развития. Указанные показатели харак- 
теризуют ресурсную составляющую инновационного потенциала РИС в виде институциональных, кластерно-отраслевых, инфраструктурных и финансовых ресурсов.

Информационная подсистема РИС характеризуется показателями развития информационного фактора формирования инновационного потенциала РИС. Указанные показатели характеризуют ресурсную составляющую инновационного потенциала РИС в виде информационного ресурса.

Организационно-управленческая подсистема РИС характеризуется показателями развития организационного фактора формирования инновационного потенциала РИС. Указанные показатели характеризуют ресурсную составляющую инновационного потенциала РИС в виде организационного ресурса.

Ресурсная подсистема РИС характеризуется показателями развития природно-ресурсного фактора формирования инновационного потенциала РИС. Указанные показатели характеризуют ресурсную составляющую инновационного потенциала РИС в виде природного ресурса.

\section{Заключение}

1. Использование факторного подхода к анализу предпосылок формирования инновационного потенциала хозяйственной системы позволило выделить группу трансформационных (представлены $A, T, R n)$ и трансакционных (представлены Ins, $O, \operatorname{Inf}$ ) факторов, способствующих формированию указанного потенциала. Исторической формой человеческого фактора является человеческий капитал, где составной его частью является интеллектуальный капитал в виде ресурсов интеллектуальной деятельности, который способствует формированию интеллектуального потенциала, характеризующего внутренние возможности развития инновационного потенциала региональной экономики. Анализ интеллектуального потенциала регионов ЮФО выявил незначительный его уровень, а степень его влияния на ВРП невысокая. В этой ситуации органам государственной власти целесообразно определить приоритеты в развитии человеческого капитала региона и разработать дифференцированные меры государственной поддержки человеческого капитала применительно к регионам ЮФО в зависимости от уровня развития их интеллектуального потенциала.

2. Технический фактор, способствующий формированию инновационного потенциала хозяйственной системы, реализует ресурсный элемент инновационного потенциала, что определяет результат его реализации в виде наукоемких производств, где направления технологических изменений обусловлены отраслевой и технологической специализациями и различаются в зависимости от степени их наукоемкости. Отраслевая специфика в отношении источников инноваций и технологий характеризуется технологическими траекториями инновационного развития регионов ЮФО, которые имеют тенденцию к сближению, вследствие чего целесообразно поддерживать высокий уровень технологизации экономики регионов ЮФО посредством заимствования технологий, а также перейти от системы закрытых инноваций к открытым.

3. Природный фактор играет важную роль в процессе формирования инновационного потенциала хозяйственной системы, определяет его технико-технологическую базу и влияет на масштабы инновационной деятельности. Природные ресурсы воздействуют на инновационный потенциал теми компонентами природной среды, которые используются в качестве средств производства или предметов потребления. Роль природно-ресурсного фактора в структуре инновационного потенциала и инновационной системы возрастает при преобладании добывающих отраслей и снижается по мере повышения степени обработки сырья.

4. Человеческий фактор, объединяющий и интегрирующий функции технико-технологического, организационного и природного факторов, способствует развитию инновационного потенциала хозяйственной системы. Пары связей на основе взаимосвязанных функций образуются между человеческим и техническим, человеческим и организационным, человеческим и природным факторами, а также техническим, организационным и природным факторами развития инновационного потенциала. Взаимосвязи между указанными факторами, влияющими на развитие инновационно- 
го потенциала, определяются наличием прямых и обратных связей, объединяемых их общим функциональным назначением воспроизводства инновационной деятельности.

\section{СПИСОК ЛИТЕРАТУРЫ}

Бабурин, В. Л. Инновационные циклы в российской экономике / В. Л. Бабурин. - М. : Едиториал УРСС, 2002. - 120 с.

Белова, Л. Г. Инновации в мировой экономике / Л. Г. Белова. - М. : Кнорус, 2019. - 148 с.

Бойко, И. В. Фундаментальные основы инновационной экономики (методологический, исторический и эмпирический контекст) / И. В. Бойко. - М. : МАКС Пресс, 2005. - 308 с.

Большая Советская Энциклопедия : 3-е изд. - М. : Эксмо, 2008. - 672 с.

Большов, А. Г. Инновационный потенциал современного общественного воспроизводства / А. Г. Большов. - М. : Издательско-торговая корпорация «Дашков и $\mathrm{K}^{\circ} », 2007 .-52$ с.

Доклад о развитии человеческого потенциала в Российской Федерации за 2004 год / под общ. ред. проф. С. Н. Бобылева. - М. : Весь Мир, 2004. $160 \mathrm{c}$.

Евченко, А. В. Прогнозирование и программирование социального развития региона в переходной экономике: ресурсный подход / А. В. Евченко, Э. Н. Кузьбожев ; науч. ред. д-р экон. наук. проф. Э. Н. Кузьбожев. - Курск : Изд-во РОСИ, 2000.-216 c.

Иншаков, О. В. Теория факторов производства в контексте экономики развития : научный доклад на Президиуме МАОН (г. Москва, 29 ноября 2002 г.) / О. В. Иншаков. - Волгоград : Изд-во ВолГУ, 2002. - 92 с.

Келле, В. Ж. Инновационная система России: формирование и функционирование / В. Ж. Келле. М. : Едиториал УРСС, 2003.-148c.

Кокурин, Д. И. Инновации и России: институциональный анализ (проблемы собственности, рынка и налогового стимулирования) / Д. И. Кокурин, В. М. Шепелев. -М. : ИНИЦРоспатента, 2002.$399 \mathrm{c}$.

Могилевский, В. Д. Методология систем: вербальный подход / В. Д. Могилевский ; Отд-ние экон. РАН ; науч.-ред. совет изд-ва «Экономика». М. : Экономика, 1999. - 251 с.

Наука и инновации // ЦБСД. Официальная статистика. - Электрон. текстовые дан. - Режим доступа: https://www.gks.ru/folder/14477. - Загл. с экрана.

Сигов, И. И. Типология региональных систем / И. И. Сигов, Л. П. Совершаева, Е. Г. Слуцкий. -
СПб. : Ин-т «Северо-Запад» МООО «Знание» СПб. и ЛО., ГУАП, 2007. - 84 с.

Суглобов, А. Е. Сетевая модель Российской национальной инновационной системы / А. Е. Суглобов, Е. В. Смирнова. - М. : ИНФРА-М, 2019. $-245 \mathrm{c}$

Фоломьев, А. Н. Прогресс российской экономической науки : Наука в России: современное состояние и стратегия возрождения / А. Н. Фоломьев. - М. : Логос, 2004. - 167 с.

Шмелев, В. Л. Инновационное развитие экономических систем: проблемы и перспективы / В. Л. Шмелев. - Ижевск : Изд-во ИжГТУ, 2006. $-192 \mathrm{c}$.

\section{REFERENCES}

Baburin V.L. Innovatsionnye tsikly $v$ rossiyskoy ekonomike [Innovation Cycles in Russian Economy]. Moscow, The Editorial URSS Publ., 2002. 120 p.

Belova L.G. Innovatsii v mirovoy ekonomike [Innovations in the World Economy]. Moscow, Knorus Publ., 2019. 148 p.

Boyko I.V. Fundamentalnye osnovy innovatsionnoy ekonomiki (metodologicheskiy, istoricheskiy $i$ empiricheskiy kontekst) [Fundamental Basis of Innovation Economy (Methodological, Historical and Empirical Context)]. Moscow, MAKS Press, 2005. 308 p.

Bolshaya Sovetskaya Entsiklopediya [Great Soviet Encyclopedia]. Moscow, Eksmo Publ., 2008. 672 p.

Bolshov A.G. Innovatsionny potentsial sovremennogo obshchestvennogo vosproizvodstva [Innovation Capacity of the Modern Social Reproduction]. Moscow, Izdatelsko-torgovaya korporatsiya «Dashkov i $\mathrm{K}^{\circ} », 2007.52 \mathrm{p}$.

Bobylev S.N., ed. Doklad o razvitii chelovecheskogo potentsiala $v$ rossiyskoy federatsii za 2004 god [Report on the Human Potential Development in the Russian Federation for 2004]. Moscow, Ves Mir Publ., 2004. 160 p.

Evchenko A.V., Kuzbozhev E.N., ed. Prognozirovanie $i$ programmirovanie sotsialnogo razvitiya regiona $v$ perekhodnoy ekonomike: resursnyy podkhod [Forecasting and Programming of the Regions Social Development in Transition Economy. Resource Approach]. Kursk, Izd-vo ROSI, 2000. 216 p.

Inshakov O.V. Teoriya faktorov proizvodstva $v$ kontekste ekonomiki razvitiya: nauchnyy doklad na Prezidiume MAON (g. Moskva, 29 noyabrya 2002 g.) [Production Factors Theory in the Context of Development Economics: Scientific Report at the Presidium of 
the International Academy of Organizational Sciences (Moscow, November 29, 2002)]. Volgograd, Izd-vo VolGU, 2002. $92 \mathrm{p}$.

Kelle V.Zh. Innovatsionnaya systema Rossii: formirovanie i funktsionirivanie [Russias Innovation System: Development and Functioning]. Moscow, Editorial URSS Publ., 2003. 148 p.

Kokurin D.I., Shepelev V.M. Innovatsii v Rossii: institutsionalnyy analiz (problemy sobstvennosti, rynka i nalogovogo stimulirovaniya) [Innovation in Russia: Institutional Analysis (Problems of Property, Market and Tax Stimulation)]. Moscow, INITs Rospatenta, 2002.399 p.

Mogilevskiy V.D. Metodologiya system: verbalnyy podkhod [Methodology of Systems: Verbal Approach]. Moscow, Ekonomika Publ., 1999. 251 p.

Nauka i innovatsii [Science and Innovations]. TsBSD. Ofitsialnaya statistika [Central Base of Statistics. Official Statistics]. URL: https://www. gks.ru/folder/14477.
Sigov I.I., Sovershaeva L.P., Slutskiy E.G. Tipologiya regionalnykh system [Typology of Regional Systems]. Saint Petersburg, Institut «SeveroZapad» MOOO «Znanie» SPb. i LO., GUAP, $2007.84 \mathrm{p}$.

Suglobov A.E., Smirnova E.V. Setevaya model Rossiyskoy natsionalnoy innovatsionnoy sistemy [Network Model of the Russian National Innovation System]. Moscow, INFRA-M Publ., 2019. $245 \mathrm{p}$.

Folomyev A.N. Progress rossiyskoy ekonomicheskoy nauki: Nauka v Rossii: sovremennoe sostoyanie $i$ strategiya vozrozhdeniya [Progress of the Russian Economics. Science in Russia: Present State and Recovery Strategy]. Moscow, Logos Publ., 2004. 167 p.

Smelev V.L. Innovatsionnoe razvitie ekonomicheskikh sistem: problemy $i$ perspektivy [Innovation Development of Economic Systems: Problems and Prospects]. Izhevsk, Izd-vo IzhGTU, 2006. 192 p.

\section{Information About the Authors}

Igor V. Antonenko, Candidate of Sciences (Economics), Associate Professor, Department of Economic Theory, World and Regional Economics, Volgograd State University, Prosp. Universitetsky, 100, 400062 Volgograd, Russian Federation, AntonenkoIV@volsu.ru, https://orcid.org/0000-0002-8379-3477

Tatiana S. Sidorovich, Candidate of Sciences (Philology), Associate Professor, Department of Translation Theory and Practice, Volgograd State University, Prosp. Universitetsky, 100, 400062 Volgograd, Russian Federation, sidorovich@volsu.ru, https://orcid.org/0000-0002-1905-4258

\section{Информация об авторах}

Игорь Владимирович Антоненко, кандидат экономических наук, доцент кафедры экономической теории, мировой и региональной экономики, Волгоградский государственный университет, просп. Университетский, 100, 400062 г. Волгоград, Российская Федерация, AntonenkoIV@volsu.ru, https://orcid.org/0000-0002-8379-3477

Татьяна Станиславовна Сидорович, кандидат филологических наук, доцент кафедры теории и практики перевода, Волгоградский государственный университет, просп. Университетский, 100, 400062 г. Волгоград, Российская Федерация, sidorovich@volsu.ru, https://orcid.org/0000-0002-1905-4258 